\title{
A REORGANIZAÇÃO TERRITORIAL ÁTICA SOB CLÍSTENES: A DEMOCRACIA COMO ENFRAQUECIMENTO DOS PODERES PA- RENTAL-ARISTOCRÁTICOS
}

Bruno D’Ambros ${ }^{1}$

\begin{abstract}
Resumo: Mostramos neste artigo que a democracia grega nasceu efetivamente com a reorganização territorial ática de Clístenes em 508 a.C., através do enfraquecimento dos genoi e phratriai em prol dos demoi. A democracia, assim, desde seu surgimento, parece ter sido uma tentativa de solução para o problema semelhante do conflito entre a distribuição de poder local e regional.

Palavras-chave: Clístenes, Democracia, Grécia antiga, Oligarquias.
\end{abstract}

A escassa produção bibliográfica histórica sobre o tema do nascimento da democracia na Grécia Antiga por vezes gera certa simplificação da temática, criando uma idealização da democracia participativa grega e esquecendo os variados elementos que a constituíram. Sem a adequada compreensão dos detalhes históricos que compuseram o nascimento da democracia, arriscamos dizer, é quase impossível compreender adequadamente Platão, Xenofonte, Aristóteles e toda a produção filosófica subsequente sobre o tema da política. As várias críticas que os filósofos antigos fizeram à democracia grega advém de muitos elementos históricos factuais que não estão, naturalmente, presentes nos textos destes pensadores e só podem ser compreendidos à luz da história política grega.

Heródoto, em seu relato fictício na sua Histórias, relaciona três reis persas - Otanes, Megabises e Dario - com, respectivamente, os três regimes políticos clássicos - democracia, aristocracia e monarquia. Este relato ajudou a consolidar no imaginário grego estas três formas de governo e já nele se percebe uma valoração negativa da democracia. Isócrates, em seu Evágoras, também vê negativamente a democracia grega por seu caráter igualitarista, porém elogia Sólon e Clístenes, que em sua opinião foram homens que foram 
capazes de construir uma cidade-estado longe da monarquia. Xenofonte, nos Memoráveis e Ciropédia, despreza a democracia, que para ele era um regime calcado na indisciplina popular e, portanto, um regime titubeante. A famosa crítica platônica à democracia, na República, não inova exceto na sua teoria da degenerescência dos regimes políticos, partindo do melhor para o pior, ou seja, a democracia; esta seria ruim porque se baseia num homem sem virtude. Aristóteles, em sua Política, rejeita a teoria platônica da degenerescência das formas de governo e afirma que a democracia é uma forma de governo degenerada que exclui o interesse comum e beneficia o interesse de uma classe particular, os mais pobres.

Em suma, percebe-se que a democracia, ao menos para as classes cultas, não era um regime bem. No entanto se atentarmos somente para os argumentos presentes nos textos destes autores citados excluindo o contexto histórico anterior, não compreenderemos esta antipatia à democracia em sua totalidade. É preciso, portanto, voltar-se para os acontecimentos históricos.

O principal evento para a consolidação da democracia, além das reformas anteriores de Sólon e dos Pisistrátidas, foi, sem dúvida a reforma territorial sob Clístenes, ocorrida por volta de 508 a.C. Foi esta reforma que, ao reconfigurar a demografia ática, enfraqueceu os laços parentais das famílias aristocráticas áticas e possibilitou a participação política efetiva nas eleições e nas instituições democráticas atenienses. $\mathrm{O}$ que houve, em outros termos, foi que os novos demoi nascentes, como nova divisão territorial administrativa, se contrapôs com a divisão familiar tradicional de parentesco denominada genos, o que contribuiu para a exacerbação da antítese entre uma aristocracia familiar local estabelecida e uma democracia política translocal introduzida. ${ }^{2}$ Todo o debate filosófico político concernente sobre a democracia tinha como pano de fundo os núcleos de gens na Grécia antiga e a nova configuração demográfica de Clístenes, os demoi.

Clístenes nasceu por volta de 570 a.C. e era membro do clã dos Alcmeônidas, neto do tirano Clístenes de Sícion, tio de Péricles e avô de Alcebíades. Quanto ao seu legado, Clístenes tomou uma série de medidas reformatórias, principalmente no que tange à reorganização política do território da Ática mudando a organização política ateniense, que era baseada em quatro tradicionais tribos com fortes laços de parentesco entre si, que foram responsáveis pelas tiranias anteriores. A fim de impedir que a tirania se

2 Sobre a diferença entre $\gamma \varepsilon ́ v o \varsigma$ e $\delta \tilde{\eta} \mu o \varsigma$ na Ática clássica faz-se mister conferir o capítulo X da parte II da obra de Fustel de Coulanges (2009), já bem conhecida entre os helenistas e latinistas, onde o autor defende a tese de que a gens era a família em sua primitiva organização de parentesco e unidade e não, como se pensava na época, um artifício administrativo de relações de parentesco. 
instalasse novamente através destas relações de parentesco, Clístenes dividiu a Ática em dez tribos de acordo com sua area de residência, o seu dèmos. Estas reformas territoriais foram na verdade uma "dessacralização da pátria" (KERCKHOVE, 1980, p. 27) e consequência do processo de racionalização em curso na Grécia Arcaica (D’AMBROS, 2014).

Os principais feitos de Clístenes durante seu arcontado foram basicamente seis: a reorganização demográfica do território ático; o conseqüente fortalecimento dos dèmos em detrimento das antigas phratriai; a reorganização da boulé em 500 participantes; a reorganização da dikasteria, a corte popular; a instituição do ostracismo e a cunhagem do conceito de isonomia que, durante o século $\mathrm{V}$, iria desembocar no conceito de democracia.

Quanto a estas outras reformas, o estabelecimento de corpos legislativos feitos de indivíduos escolhidos por eleição foi também mais um atentado contra o parentesco e a hereditariedade aristocrática. Ainda, sua reorganização da Boulê, que primariamente foi feita por 400 membros para 500 membros, 50 de cada tribo e a introdução do juramento boulético que propunha antecipadamente a agenda a ser discutida na ekklésia, foram importantes para esta desestabilização aristocrática. A reorganização do tribunal da dikasteria e a criação do ostracismo, usado pela primeira vez em 487 a.C., com a finalidade de expulsar da cidade qualquer um que ameaçasse a democracia, foram mecanismos úteis para o enfraquecimento do poder parental-aristocrático.

A ascensão de Clístenes ao arcontado se deu após a expulsão de Híppias de Atenas, quando Iságoras entra na disputa pelo arcontado com Clístenes, ambos aristocratas. Iságoras aliou-se com o rei Cleomenes I de Esparta e exilou Clístenes junto com 700 famílias e tornou-se arconte epônimo em 507 a.C. Seu grande erro, porém, foi tentar dissolver a boulé, ${ }^{3}$ que resistiu e angariou o apoio do povo e forçou Iságoras a fugir para a Acrópolis que lá permaneceu por dois dias, sendo expulso no terceiro, junto com os espartanos aliados (HERÓDOTO, Histórias, V, 72.1-2). Clístenes, então, junto com os outros exilados, retornou a Atenas e tornou-se arconte com apoio do povo e dos aristocratas hetairoi (cavalaria).

Conflitos entre aristocratas, como entre Iságoras e Clístenes, estava se tornando "fora de moda" (BUCKLEY, 2010, p. 118). O povo, de modo geral e igualmente a parcela de nobres por mérito financeiro, estava enfastiada de disputas entre facções aristocráticas que, não percebendo a mudança dos tempos, ainda sustentava valores e códigos de honra anacrônicos. Clístenes, 
arguto político e membro da aristocracia, percebeu isso já durante o período de tirania, onde os tiranos, para se manter no poder, adotavam medidas populistas que não os tornavam dependentes dos humores inconstantes das facções aristocráticas, mas do próprio povo. E lidar com o povo ignorante cujos interesses são mínimos é muito mais fácil que lidar com uma aristocracia com infinitos interesses econômicos e políticos e códigos de honra fastidiosos.

Inspirado no bem suscedido populismo ${ }^{4}$ precedente dos pisistrátidas, Clístenes toma medidas igualmente populistas para se manter no poder, desagradando, naturalmente, a classe aristocrática, da qual ele mesmo fazia parte. Dentre estas medidas, as principais foram duas, a reforma demográfica e a ampliação dos poderes da ekklesia. Heródoto (HERÓDOTO, Histórias, V, 66.2; 69.2) sublinha este caráter oportunista das medidas de Clístenes e igualmente Aristóteles, quando diz que "Clístenes trouxe o povo para o seu lado cedendo o controle do Estado para o plethos (plebe)" (ARISTÓTELES, Constituição dos atenienses, 20.2). Portanto, apesar de Clístenes ser considerado o real fundador da primeira democracia na história, seus interesses não foram altruístas, mas permeados de interesses pessoais e aristocráticos ou, mais amenamente, uma "combinação de auto-interesse e acuidade pública" (BUCKLEY, 2010, p. 120).

Assim, a democracia ateniense nasce propriamente com Clístenes, em função de sua reforma demográfica do território Ático. Os principais motores destas reformas foram dois que se inter-relacionam: o problema da cidadania ateniense e o problema das unidades parental-aristocráticas. Passemos, a seguir, a explicá-las.

Durante o arcontado de Sólon, muitos estrangeiros vieram para Atenas, por sua prosperidade crescente com sua abertura econômica, para trabalhar nos mais diversos ramos, sendo o principal o artesanato. Igualmente, durante

$4 \mathrm{O}$ populismo, termo moderno, é um fenômeno que liga-se diretamente à tirania. O tirano era essencialmente um populista: estava ao lado do povo e contra os aristocratas. Heródoto (V, 92,6) diz que a sanha do tirano é essencialmente a igualdade: "cortar todas as espigas maiores que as outras". Glotz (1988, p. 92) resume magistralmente qual era, de fato, o objetivo do tirano: "reduzir os poderes da aristocracia e exalçar os humildes". Por isso, na tipologia política platônica à democracia não é reservado a ela um bom lugar, pois o intervalo entre a democracia e o populismo e, portanto à tirania, é curto. O povo, no baixo medievo grego, cultuava deuses locais ctônicos, sendo um deles, Dioniso (lembremos que, como Cristo, ele desceu ao Hades e ressuscitou, segundo o Hino Homérico LIII). A aristocracia cultuava deuses com caráter universal, os deuses olímpicos. Para agradar o povo, Pisístrato promove os cultos ctônicos populares, sendo o principal o culto a Dioniso, construindo um templo e instituindo o festival da Grande Dionisia, onde, em 535 a.C., foi encenado a primeira tragédia, tendo como vencedor Thespis de Icária. Assim nasce oficialmente o culto a Dioniso e a Tragédia grega: sob os auspícios do populismo tirânico (cf.: GLOTZ, 1988, p. 93). 
os pisistrátidas, muitas novas pessoas vieram para Atenas para servir como mercenários do exército público. Assim, durante todo o século VI Atenas recebeu uma quantidade crescente de estrangeiros que, no governo de Sólon vieram para trabalhar como artesãos de vasos, e no governo dos pisistrátidas vieram para trabalhar como mercenários no exército público; estes foram os famosos métoikos (estrangeiros).

Durante o governo de Clístenes Atenas já era habitada pelos netos e bisnetos destas pessoas, no entanto, sem cidadania ática ainda. Assim tínhamos três gerações de estrangeiros que ainda não tinham a cidadania ateniense plena. Atenas, durante o século VI a.C., teve um crescimento demográfico significativo e a propaganda política dos pisistrátidas em transformar Atenas no centro cultural Ático foi bem-sucedida, ao trazerem os festivais dionisíacos, teatro e os jogos olímpicos para a cidade. Desde modo, além dos descendentes daqueles estrangeiros que vieram para Atenas sob Sólon e os pisistrátidas, sob Clístenes afluíram para Atenas muitos outros estrangeiros.

A única prova formal de cidadania ateniense antes de Clístenes eram as fratriai, que reivindicavam para si uma origem mítica, como seus nomes atestam. Assim, quando Clístenes fez a reforma geopolítica ática criando os demoi, ele automaticamente aboliu o antigo critério de cidadania criando um novo, os demoi (BUCKLEY, 2010, p. 120). O termo deme tem um sentido muito específico na Ática, pois, de fato, se refere "unidade política associada com as reformas de Clístenes" (TRAILL, 1975, p.73).

Para compreender a natureza e extensão da reforma geopolítica ática de Clístenes em deme é preciso compreender a natureza das quatro unidades parental-aristocráticas áticas anteriores, phylai, phratriai, genē e oikoi ou anchisteia. Eric Voegelin (2012, p. 190) chama-as de "estruturas gentílicas" de sinecismo da civilização helênica e as apresenta em níveis, da maior para a menor, respectivamente. ${ }^{5}$ Estas estruturas gentílicas da civilização helênica tinham características tribais e foram determinantes do processo de sinecismo ático, ou seja, na união dos vários vilarejos áticos em torno de um centro político único, Atenas, durante o século $\mathrm{V}$ a.c.

Ao longo do século VII a.c. as phratriai são a base da sociedade, englobam também os genē e se legitima como poder político, tendo regras próprias, podendo promulgar decretos próprios, possuir bens e dignitários,

5 Contudo não sabemos exatamente se os philai eram partes das phratriai ou, contrariamente, se as phratriai eram parte das philai (LAMBERT, 1993, p. 1516). 
tem seu próprio sacerdote e culto. As lideranças das phratriai eram hereditárias e, portanto, não-democráticas (BUCKLEY, 2010, p. 122). As phratriai eram o foco da aristocracia e, uma vez que a aristocracia era um problema para o povo, logo eram igualmente o foco do problema. As phratriai podiam dividir-se ou fundir-se conforme sua fraqueza ou força política e segundo as circunstâncias (LAMBERT, 1993, p. 11) e esta grande mobilidade espontânea foi provavelmente o motivo que as fizeram sobreviver durante os 200 anos de democracia como "organizações extra-urbanas" (JONES, 1999, p. 210).

A fundação das phratriai foi atribuída à figura mítica de Ion, personificação da identidade jônica (LAMBERT, 1993, p. 3). Atenas estava organizada em quatro tribos jônicas agrupadas em phratriai e genē baseadas num parentesco mítico com algum herói (FINE, 1983, p. 229). Este recurso genealógico a um ancestral mítico comum foi recorrente em todas as phratriai e pode se atestar tanto pelo sufixo patronímico -idai nos nomes das phratriai, como Alkmeonidai e Demotionidai como pelo famoso festival de Apatouria, cujo nome derivaria de homopatoria, ou seja,"mesmo pai" (LAMBERT, 1993, p. 8). Apesar de o recurso genealógico-mítico não ser verdadeiro, como hoje compreendemos a noção de verdade como correspondência, de fato as phratriai consistiam de pessoas com uma ancestralidade comum, chamados homogalaktes, e a membresia nas phratriai não era reservada somente aos ricos eupatridai (FINE, 1983, p. 186) mas estendida a todos os que vinham a pertencer a uma phratriai. Deste modo as phratriai eram organizações de parentesco primordialmente constituídas por phráter, vizinhos próximos e amigos de família. Há três evidências, segundo Lambert (1993, pp. 4-5) da existência das phratriai áticas: trinta inscrições arqueológicas preservadas, obras tardias dos séculos V e IV a.C., em especial Isaeus e Demóstenes e scholia variados, como os ensaios de Plutarco, Pausanias e Ateneu. Em Homero a fratria é uma "subdivisão da tribo" e uma "base de organização militar", de modo que o homem sem fratria é considerado um "fora de lei" (VIAL, 2013, p.189). A palavra phrater significa literalmente irmão, mas em Homero não se usa a palavra phrater para se referir a irmão, mas sim adelphos e kasignetos (FINE, 1983, p. 35). O termo phratria é mencionado pela primeira vez na Ilíada (II, vv. 362-363; IX, vv. 63-64) quando Nestor fala a Agamenon para dividir os homens por tribos e phratriai. Uma hipótese para a origem das phratriai bem aceita é a de que na "Era das Trevas" grega os nobres agrupados em gene organizaram seus dependentes em phratriai para melhor controle, cada uma estando sob o domínio de um ou mais gene (FINE, 1983, p. 186). Assim, a organização em phratriai formam um modo de organização dos genè e, de fato, as phratriai organizaram a vida social e política grega desde sua 
aparição, por volta de 2000 a.C, até seu fim no segundo século II a.C., como atesta uma inscrição em uma colônia grega em Nápoles.

As outras estruturas gentílicas, phylai, genē e anchisteia, são partes constituintes do que serão as poleis futuramente. À medida que a noção de sujeito vai tomando escopo - como se pode atestar pela epopéia, lírica e tragédia até seu ponto culminante com a filosofia - o mundo tribal aristocrático vai dando lugar ao mundo das poleis democráticas. $\mathrm{O}$ sujeito "[...] sempre permaneceu numa posição de mediação por meio dos parentescos sanguíneos tribais fictícios e estreitos no interior da pólis" (VOEGELIN, 2012, p. 189).

Clístenes mudou a situação política ática mudando a situação geopolítica. Agora o centro das decisões políticas não eram mais as phratriai, mas os demoi. Clístenes dividiu a Ática em três regiões geopolíticas: Paralia, Mesogeia e Astu. E cada uma destas áreas foi subdividida em dez partes chamadas tritías ${ }^{6}$ que, por sua vez, englobavam um certo número de demes (BRAADEN, 1955, p. 22). De acordo com Braaden (1955, p. 28), "as tritías eram áreas geográficas compactas e em alguns lugares contíguas". A subdivisão ática foi uma forma de "misturar o povo" (BUCKLEY, 2010, p. 128; BRAADEN, 1995, p. 23). As reformas de Clístenes "podem ter intentado transcender barreiras locais juntando homens dos distritos rurais, urbanos e costeiros e desenvolver um sentimento de união" (HIGNETT, 1952, p. 141). Esta divisão ática foi a maneira achada para solucionar os conflitos parental-aristocráticos entre as diversas facções e partidos. ${ }^{7}$

A principal diferença entre as phratriai e os demoi era a "constituição democrática" (BUCKLEY, 2010, p.123) destes últimos. Todos os temas concernentes aos demoi eram decididos não mais por uma pequena phratria seleta, mas por todo o demos.

Alguns especialistas sustentam que Clístenes, com sua reforma demográfica, desejava aumentar o poder das cidades e outros que, ao contrário,

6 As dez era a dos Erectidas, Egeus, Pandion, Leônides, Acamantes, Oineis, Cecrópides, Hipotoontes, Eântides e Antíoques e estavam espalhadas por todo o território ático, em diferentes locais, tendo, muitas vezes, a mesma tribo, em locais diferentes, totalizando, assim, trinta tritías. Na mesma tritía havia vários demoi e se crê ter havido cerca de 140 dēmoi em toda a Ática. Cada tribo é composta por três tritías, a da costa, cidade e planície. Cada tritía foi nomeada segundo o demo dominante.

7Alguns partidos regionais do século VI a.C. eram: pedieis, cujo núcleo estava concentrado na área de planície e tinha Licurgo como líder; paralioi, cujo núcleo era a área costeira e era famoso por ser a região dos Alcmeônidas; e, por fim, os hyperacrioi, os "além dos montes". Clístenes desejava quebrar a velha rivalidade entre os pediakoi, paralioi e diakrioi e a influência dos eupatridai (BRAADEN, 1955, pp. 23- 25). 
ele desejava diminuir. De fato, Clístenes estava mais interessado, dentre as três grandes áreas em que a Ática foi divida, na área urbana provavelmente porque a maior parte das famílias nobres eram de centros urbanos (BRAADEN, 1955, pp. 28-29). Além disso, "as tritías da Cidade consistiam de somente um demos que, como a evidência arqueológica mostra, era a sede política dos Alcmeônidas" (BUCKLEY, 2010, p. 127), ou seja, a própria facção de Clístenes:

Deste modo as reformas tribais de Clístenes foram um grande, senão o mais importante, fator no desenvolvimento da democracia ateniense, mas foram também um meio de fortalecer a permanência política dos Alcmeônidas às custas de seus oponentes (BUCKLEY, 2010, p. 128).

Estas famílias mantiveram influência política sobre o território de onde vieram, apesar de suas residências estarem em áreas urbanas. Alguns alegam, como Braaden (1955, p. 29) que a reforma territorial de Clístenes não foi um meio de beneficiar a plebe, mas os aristocratas, porque "era necessário inventar um sistema pelo qual elas pudessem ser espalhadas por todas as tribos, enquanto ainda usando localidade como a base para a cidadania".

As rivalidades e conflitos entre as facções podem ter sido causadas pela ambição de poucas famílias ou clãs aristocráticos que eram capazes de usar seus domínios de certas regiões da Ática como arma política. Clístenes percebeu que estes blocos regionais de poder, com seus líderes aristocráticos sustentados em poder pode seus amigos e dependentes pela rede de velhas lealdades e alianças, eram o maior obstáculo para a estabilidade política. Consequentemente, houve uma radical reorganização do corpo citadino e por isso das quatro tribos jônicas, sob os fundamentos que a dependência política do povo comum poderia somente ser quebrada pela separação política de seus líderes aristocráticos (BUCKLEY, 2010, p. 126).

A artificialização do território através de uma reforma geopolítica foi o modo encontrado para enfraquecer o poder das fratrias, fortalecer o poder do povo e "quebrar os fortalecidos poderes regionais destes clãs aristocráticos e suas facções, acabando com as funções políticas das fratrias e das velhas tribos [...] (BUCKLEY, 2010, p. 122). No entanto, ao mesmo tempo, foi um modo de fortalecer o poder de uma fratria específica, a própria de Clístenes, e descentralizar as decisóes políticas e unificar o estado. Poderíamos dizer, assim, que a democracia ateniense foi conseqüência de uma demografia antes de tudo. 
Como dito acima, um dos problemas sociais mais urgentes resolvidos sob Clístenes ao final do século VI eram os novos cidadãos sem cidadania ateniense plena. A nova base de cidadania instituída por Clístenes foi a localidade de nascimento e isso facilitou a inclusão de novos cidadãos (BRAADEN, 1955, p. 22). Com as phratriai enfraquecidas, a base de confiança para a cidadania agora não eram mais o parentesco fictício com algum herói, mas simplesmente o demos ao qual alguém fazia parte. Os deme garantiriam cidadania ateniense não só para antigos habitantes, mas também para os novos, conforme relata o próprio Aristóteles (Constituição dos atenienses, 21.4). Voegelin também nos confirma ao dizer que "a cidadania agora dependia do pertencimento a um dos demoi" e diz que a consequência geral deste feito foi uma "democratização bem-sucedida da constituição, dissolvendo o poder da antiga estrutura gentílica (VOEGELIN, 2012, p.190).

Além deste alargamento da cidadania a reforma demográfica clisteneana repercutiu na organização militar pois agora os "generais de qualquer tribo poderia vir de qualquer uma das três regiões da Ática" (BRAADEN, 1955, p. 26). A reforma territorial de Clístenes foi "um sistema pelo qual os Eupatridai, seus inimigos, talvez, mas ainda homens de habilidade, pudessem ser usados para favorecer na posição militar e na nova e poderosa posição de Prytaneis" (BRAADEN, 1955, p. 30).

Este é um sistema extremamente complexo e foi implantado por Clístenes com a finalidade de abolir os privilégios patronímicos em favor dos demonímicos, o que aumentou o senso de pertença a um dēmos nos indivíduos, ficando as relações familiares de genos cada vez mais tênues. O dèmos, portanto, foi uma divisão territorial artificial para impedir a força política dos genos. Poderíamos dizer que esse conflito entre genos e demos é o conflito entre a lei do Estado e o direito familiar, ou ainda, o conflito entre poder central e poderes regionais, que estará presente durante toda a história da política e da filosofia política, culminando em soluções futuras como federalismo e a teoria da divisão dos poderes.

Esta estratégia geopolítica se deu justamente pela excessiva força das relaçóes parentais que o genos proporcionava, frequentemente levando ao poder um membro proeminente de um genos que não legislaria em favor do público. $\mathrm{O}$ genos, assim, se tornava representante por excelência da aristocracia. Logicamente, a decisão de Clístenes não foi inicialmente bem vista, pois diluía as relaçóes familiares tradicionais do genos em troca de relaçôes artificiais novas do dèmos. O que se tornava decisivo daqui em diante para a política Ática não era mais o nascimento, a estirpe, a hereditariedade mítica reivindicada pela aristocracia. A arete saia do campo de virtudes familiares para virtudes sociais, 
sempre tendo em vista a comunidade. Clístenes, desta forma, literalmente instituiu a democracia.

O que foi então a democracia Ática antiga? Foi uma divisão territorial, uma estratégia geopolítica, em prol de todas as pessoas e não somente de grupos familiares bem instituídos. Portanto, para a democracia Ática antiga, foi de suma importância a artificialização do território. Só desta forma pode-se afrouxar os laços parentais tradicionais, que sempre tenderam a se agrupar e formar oligarquias, em prol de laços públicos, que por estarem territorialmente distantes e não terem proximidades familiares auxiliaram no sentimento de pertença territorial.

\begin{abstract}
We show in this article that Greek democracy was actually born with the Attic territorial reorganization of Clístenes in 508 b.C., through the weakening of the genoi and phratriai in favor of the demoi. Democracy, then, since its inception, seems to have been an attempt to solve the similar problem of the conflict between the distribution of local and regional power.

Keywords: Cleisthenes, Democracy, Ancient Greece, Oligarchies.
\end{abstract}

\title{
REFERÊNCIAS
}

ARISTÓTELES. Constituição dos atenienses. 2 $2^{\text {a }}$ Ed. Lisboa: Calouste Goubenkian, 2009.

BRADEEN, Donald. The trittyes in Cleisthenes' reforms. In : Transactions and proceedings of the American philological association, Vol.86, 1955, pp.22-30.

BUCKLEY, Terry. Aspects of Greek history 750-323bc : A source-based approach. London : Routledge, 2010.

COULANGES, Fustel de. A cidade antiga. São Paulo: Martin Claret, 2009.

D’AMBROS, Bruno Rodrigo. Um estudo histórico sobre a emergência da democracia como consequência do processo de racionalização na Grécia arcaica (594-508 a.C*). Orientador, Jean Gabriel Castro - Florianópolis, SC, 2014. 119 p. Trabalho de Conclusão de Curso (graduação). Universidade Federal de Santa Catarina.

FINE, John Van Antwerp. The ancient greeks: a critical history. Harvard University Press, 1983.

GLOTZ, Gustave. A cidade grega. São Paulo: Bertrand Brasil, 1988.

HERÓDOTO. Histórias, livro V. Lisboa: Edições 70, 2007

JONES, Nicholas. The associations of classical Athens: the response to democracy* Oxford University Press, 1999.

KERCKHOVE, Derrick De. A Theory of Greek Tragedy+ SubStance, Vol. 9, No. 4, Issue 29 (1980), pp. 23-36. 
LAMBERT, S.D. The phratries of Attica. Michigan Monographs in Classical Antiquity. Michigan University Press, 1993.

TRAILL, John S. The Political Organization of Attica: A Study of the Demes, Trittyes, and Phylai, and Their Representation in the Athenian Council. Hesperia Supplements, v. 14 - The Political Organization of Attica: A Study of the Demes, Trittyes, and Phylai, and Their Representation in the Athenian Council, 1975, pp. 139 169

VIAL, Claude. Vocabulário da Grécia Antiga. São Paulo: Martins Fontes, 2013.

VOEGELIN, Eric. História das ideias políticas 1: Helenismo, Roma e cristianismo primitivo. São Paulo: É realizações, 2012. 